\title{
A Study of Relationship between Symbols and Cultures from the Perspective of Linguistics
}

\author{
Li Dongxiang \\ International Exchange Department, Anshan Normal University \\ Liaoning 114007
}

\begin{abstract}
There is a close relationship between symbols and cultures, but the relationship between them and the derived relationship between cultural symbols and symbolic cultures still need to be reviewed. By analyzing from a new perspective of linguistic semiotics, this paper finds that cultural symbols refer to the signifier, representing cultural forms, while symbolic cultures refer to the signified, representing cultural meanings. Cultural symbols can spread, create and shape symbolic cultures, while the latter is the objectification of the former. Symbolic cultures and cultural symbols are the combination of forms and meanings, jointly constructing the cultural system.
\end{abstract}

Keywords-Culture; Symbol; Cultural symbol; Symbolic culture

\section{INTRODUCTION}

In the second half of 2009, a research term led by Professor Wang Yichuan and Professor Dong Xiaoping from Beijing Normal University distributed nearly 2000 questionnaires on "the most representative Chinese and foreign cultural symbols for college students nationwide", "the most popular Chinese cultural symbols in the eyes of college students nationwide" and "the most popular foreign cultural symbols for college students nationwide" in 25 universities among 18 provinces, municipalities and autonomous regions nationwide. After nearly four-month investigation, it is found that the amount of the most representative Chinese cultural symbols reach 20, and they are respectively Chinese (Chinese characters), Confucius, calligraphy, the Great Wall, the Five-Starred Red Flag, the traditional Chinese medicine, Mao Tsedong, the Forbidden City, Deng Xiaoping, the Terracotta Army, the Yellow River, The Analects of Confucius, the Summer Palace, the scholar's four jewels (writing brush, ink stick, ink slab and paper), Mogao Grottoes in Dunhuang, Records of the Historian, papermaking technique, classical poetry and Peking Opera [1].

These cultural symbols are not only just information codes but also carry certain cultural information and connotation, representing the cultural image of a country. In this case, problems come. What is the relationship between symbols and cultures? Should the combination of symbols and cultures be called symbolic cultures or cultural symbols? And what is the relationship between them? With regard to these complicated relationships, it is necessary to correctly analyze the relationship between them from the perspective of linguistics is a necessity, which is conducive to clarifying and improving the contemporary cultural system.

\section{THE RELATIONSHIP BETWEEN SYMBOLS AND CULTURES}

As for the definition of symbols, Saussure, a modern great master of semiotics, indicates that symbols include "the signifier" and "the signified". The former refers to the phonetic form of symbols, while the latter refers to meanings of symbols, and the combination of forms and meanings becomes symbols. What is more, he points out that semiotics is the study of symbolic life in social life. Morris also deems that human civilization depends on symbolic systems and symbols, as well as symbol functions and human mind cannot be separated [2]. According to Cassirer, a well-known semiotician, "art is a symbolic language, while cultures, such as language, myth, art and religion, are all created by people who use symbols, so people are not so much political animals as symbolic ones [3]. "Therefore, it's recognized that symbols are closely related to humans. Humans are symbolic, and a society consists of such cultural ideologies as language, myth, art and religion created by humans using symbols. Human mind, language and communication cannot be separated from symbols.

The word "culture" derives from its Latin root "cult", meaning "cultivation, reclamation, development and enlightenment". In Chinese, "culture" comes from "observe the sky to see the change of time; observe humanity to humanize the world" in the Book of Changes. In fact, China and the West have almost the same cultural orientation, both emphasizing "humanization". According to German jurist Samuel von Pufendorf, culture is the sum of products created by human activities in society and products depending on human and social life [4]. German philosopher Herder also believes that culture is the product of human activities and the stimulus of human activities. Therefore, culture is closely related to humans. Culture is the result of humanization, that is, culture is the product created by human's long-term engaging in social practice in history. Consequently, culture is a social and historical phenomenon.

In conclusion, both symbols and cultures are closely related to human. According to syllogism, symbols are closely related to cultures, thus, both of which are related to human activities. Once interactive relations among symbols, human and cultures are established, symbols will serve as the central bridge. People choose the representative cultural presentation form in the colorful world-symbols, which create, spread and reshape cultures in the process of regulation, development and 
solidification. In a word, people can transform natural world into a cultural one with the help of symbols, so culture is the product of humans' symbolic activities and also can be regarded as the realization of these activities.

The relationship between symbols and cultures is embodied in the following three aspects: (a) symbols can create cultures. Symbols are the carrier of cultures, while cultures are the content of symbols, which includes both material and spiritual factors. Symbols, existing as a tool, are indispensable for the creation of cultures. The expression of each culture shows a symbolic system with a specific meaning. Therefore, the creation of symbol, to some extent, is a cultural creation at a formal level. The function of symbols is that it can objectify such material aspects as the Great Wall, chi-pao and Journey to the West, so as to combine them with historical and cultural heritages, Chinese folk costumes, writers and their works and other spiritual factors. Once there are more and more objectified symbols, and they are interwoven into a symbolic network, various cultures will be formed. (b) Symbols can spread cultures. Symbols act as a bridge in the process of cultural communication. Under a certain media symbolic environment and the same symbol cognitive environment, the transmitter encodes the material culture into its symbolic form to spread cultures to the receiver, and the receiver decodes it by using common symbolic cognition as the transmitter. Once successfully decoded, effective cultural communication can be realized; otherwise, the receiver constructs a new symbol cognitive environment or the transmitter adjusts the old symbol cognitive environment so as to fit the receiver's cognitive environment. Therefore, during the spread of cultures with symbols, the media symbolic environment and the shared symbol cognitive environment play a very important role. (c) Symbols can reshape cultures. Everything is in a unity of opposites. With the development of society, the progress of all things presents a counter-balance phenomenon, which requires constant adjustment and restructuring, so does the process of constructing cultures with symbols. Once a certain material culture is solidified into a symbol, it will be spread as a nonlinguistic symbol.

\section{The RELATIONSHIP BETWEEN SyMbolic CULTURES AND CULTURAL SYMBOLS}

From the perspective of linguistics, both "cultures" and "symbols" are independent, and they can be combined freely. The combinations are "symbolic cultures" and "cultural symbols". What's the difference between symbolic cultures and cultural symbols? It will be discussed from their conceptual analysis.

"Cultural symbols", a noun phrase with attribute-adjective construction, whose attribute is cultures and adjective symbols. Literally, cultural symbols are all that can carry cultural meanings. If qualitative analysis is required, cultural symbols belong to the category of symbols. As an abstract embodiment of unique cultures for a company, a region, a nation or a country, cultural symbols are signs with certain special connotations or meanings, which are important carriers of cultural connotations. The richer cultural connotations are, the more diverse the forms of cultural symbols can be. Different classification standards present cultural symbols with different categories. According to nationality, cultural symbols can be divided into Chinese cultural symbols and foreign cultural ones. Chinese cultural symbols include Chinese (Chinese characters), the Forbidden City, the Great Wall, the classical gardens of Suzhou, Confucius, Taoism, The Art of War, the Terracotta Army, Mogao Grottoes, Tang Empire, silk, porcelain, Peking Opera, Shaolin Temple, kung fu, Journey to the West, Temple of Heaven, chairman Mao Tsedong, acupuncture and Chinese cooking. American cultural symbols comprise Wall Street, Broadway, Hollywood, McDonald's, NBA, Coca-Cola, Hilton, Marlboro, Disney, Silicon Valley, Harvard University, Thanksgiving Day, superman, the Statue of Liberty, Barbie doll, the White House, rugby, jazz, Starbucks, Wal-Mart, and so on. According to time, cultural symbols can be divided into ancient cultural symbols and modern and contemporary cultural ones. Ancient cultural symbols mainly include Chinese Calligraphy, Seal carving, the scholar's four jewels (ink slab, writing brush, paper and ink stick), Cloisonne, Chinese characters, The Book of Songs, The Songs of Chu, Tang poetry, Song $\mathrm{Ci}$, Yuan Qu, Ming and Qing fiction, Oracle Bone Inscriptions, and so on. Modern and contemporary cultural symbols mainly include liu Xiaoqing, Han Han, Cui Jian, li Zehou, Song Zuying, Jay Chou, Deng lijun, Yuan longping, Chen Jingrun, lenovo, Baidu, Mao Tsedong, Deng Xiaoping, Sun Yat-sen, and lu Xun with dual characteristics of politics and culture [5]. According to nature, cultural symbols can be divided into material cultural symbols and spiritual ones. The former mainly includes silk, porcelain, tea, temple, court, couplet, gold coin and so on, while the latter mainly includes Buddhism, Taoism, Confucianism and so on. Compared with other common symbols, cultural symbols have distinct features, which are mainly reflected in the following aspects. First of all, cultural symbols are quality products that have been refined and condensed over time. Cultural symbols are cultural deposits formed after long-term refining, which concentrate cultural connotations of a country, a region, a society or a nation. Secondly, cultural symbols are people's cultural identity. People, with common national cultural symbols, have a strong resonance, thus generating strong national confidence and pride, constructing their own cultural identity, and forming cultural identity for their own countries and nations. Finally, cultural symbols have distinctive national characteristics. Every country has the characteristics of cultural diversity, so the diverse culture must have its own characteristics. In conclusion, cultural symbols, as the typical presentation form of symbolic cultures, are the important carrier and media of cultures.

"Symbolic cultures", a noun phrase with attributeadjective construction, whose attribute is symbolic and adjective cultures. As a part of cultures, symbolic cultures refer to the cultural information presented by symbols and humans' cultural landscape. Cultures are also a strict classification system based on symbols. Therefore, it can be summarized that symbolic cultures, taking symbols as the basic element and carrying various cultural information, is a classification system regulated by human beings. As is known to all, cultures are a highly generalized symbolic meaning in humans' interactions with society. Then how are symbols transformed into cultures? According to Cassirer, humans themselves are regarded as a symbol element, so the cultural activities that people are 
engaged in, including language, art, religion, science and history, are all components based on human beings, the basic element [6]. It can be said that symbolic cultures will emerge as long as each basic element carries certain meaning. Cassirer's theory only focuses on the interior of symbol unit but does not take social factors outside symbols into account. In fact, the process of the transformation of symbols into human cultures is mainly because human beings use objects separated in space-time and the abstract similarity of events. The abstract similarity forms image schema in human brain, and then constructs an image schema network by analogy mechanism. The symbols on the schema network are not immutable. When human activities are related to a symbol, the culture represented by the symbol will be adjusted accordingly.

As for the relationship between "symbolic cultures" and "cultural symbols", it can be summarized that the former is the objectification of the latter, which refers to the product of labor created by cultural symbols in human's practical activities. The concrete manifestation is as follows: firstly, cultures are the product of human beings' social practice. Cultures are the total of material and spiritual wealth created by human beings in the course of social and historical practice [7], and they are the product of human nature objectification and externalization of human nature strength. From the perspective of the way of cultural creation, the generation and development of cultures is the process of dynamic creation of cultures. It is an interactive process, in which both long-term social practice of cultural subject and the corresponding reflection of cultural object are indispensable. From the perspective of the result of cultural creation, cultures are the result of creator's constant practice. Therefore, cultures come from society. Secondly, cultures are the objectification of human and their nature strength. Cultures are the result of humans' transformation of nature in social practice. The brand of nature is the objectification of human beings subject and their activities. However, the creation and development of cultures is not passive and mechanical. It involves human's subjective initiative. It is not only the product of the objectification of practice subject, but also the embodiment of active process of practice subject. Therefore, the emergence and development of symbolic cultures is a process of both dynamic construction and a specific historical unity of internalization and externalization. To sum up, symbols are the manifestation of cultures, and cultures are a system of the interaction of symbols, both of which are products of human's creation. Cultural symbols are the expression form of human's essential attributes, while symbolic cultures are the content thereof.

\section{CONCLUSION}

From the perspective of linguistics, it is believed that cultural symbols refer to the signifier, that is, formal representations, while symbolic cultures refer to the signified, that is, meanings and connotations. Cultural symbols, when people are engaged in, can spread, create and shape symbolic cultures, and symbolic cultures, in turn, can contain the content information of cultural symbols. Thus, symbolic cultures and cultural symbols are the combination of forms and meanings and thus can jointly construct cultural system.

\section{ACKNOWLEDGMENT}

About the author: Li Dongxiang, a lecturer of International Exchange Department in Anshan Normal University and a doctoral student in Jilin University, majoring in language and culture.

Fund project: a general project of philosophy and social science research of Anshan in 2018 (as20183081), and a key school-level project supported by Anshan Normal University in 2016 (16kyxm25).

\section{REFERENCES}

[1] Shao Peiren, Lin Qun. Gene Extraction and Feature Modeling in Chinese Culture. Journal of Xuzhou Normal University (Philosophy and Social Sciences Edition), 2012, 38(2), pp. 107-111.

[2] Guo Zongwang. Study on the Relationship between Symbol and Cultural Communication. Modern Communication, 2009(12), pp. 24+23.

[3] Zhang Liyin. Cultural Differences and Coping Strategies in CrossCultural News Dissemination. Journal of Hubei Social Sciences, 2011 (4), pp. 191-194.

[4] Zhang Jie. Basic Theoretical Analysis of Chinese Character Culture. Chinese Character Culture, 2018(7), pp. 3-4+6.

[5] China Appraises on Cultural Symbols. Mao Tsedong and Han Han are on the List-Culture, from http:big5.sznews.c.

[6] Cassirer. Philosophy in Symbolic Form, Yale University, 1953(1), pp. $69+79$.

[7] Yang Dawei, Yang Xingchen. Strengthening and Firming the Four Confidences to Win a New and Greater Victory - Learning the Party's Nineteenth Report. The Border Economy and Culture, 2018(1), pp. 1-7. 